
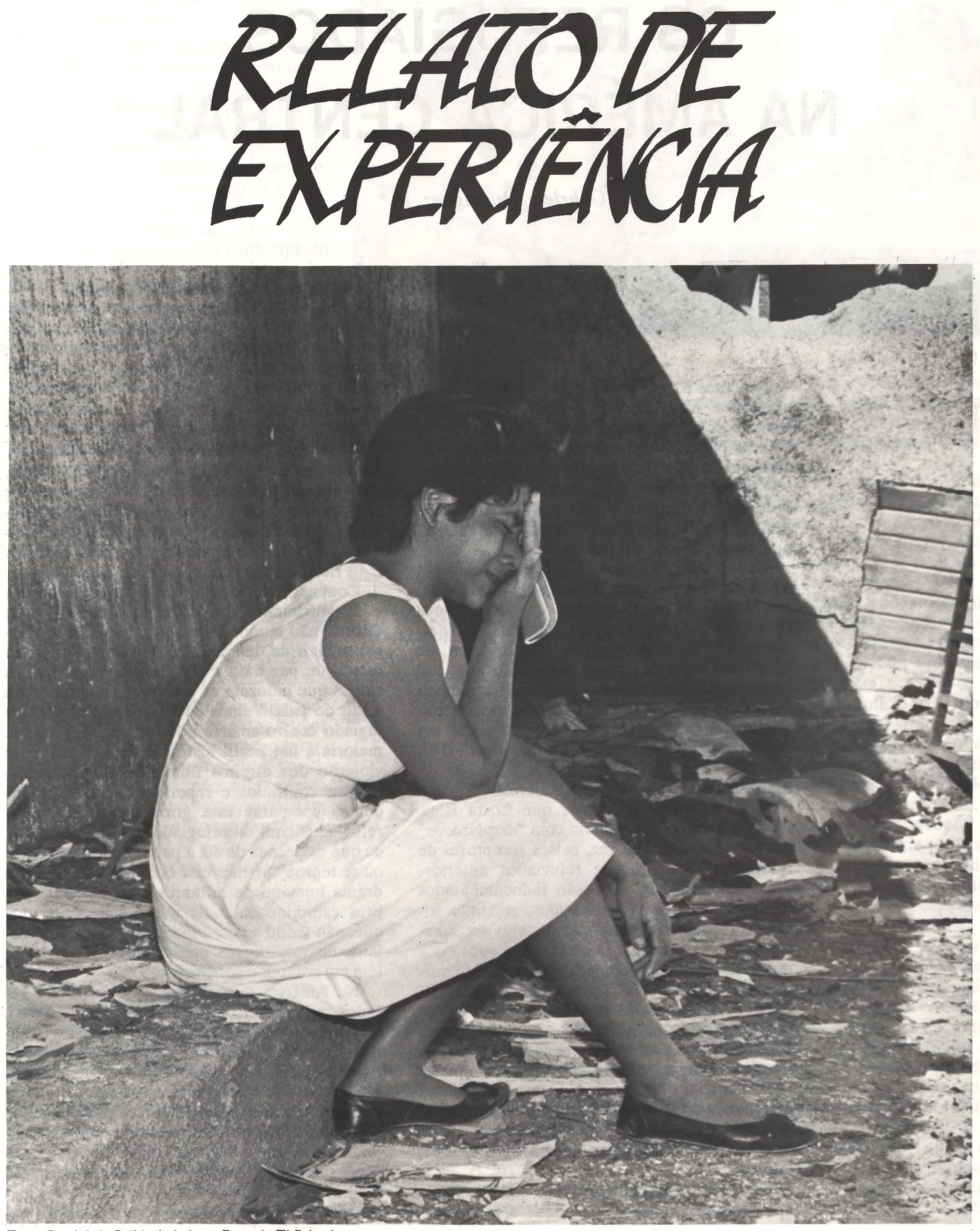


\title{
OS REFUGIADOS NA AMÉRICA CENTRAL
}

\author{
Gabriela Rodríguez P.*
}

\section{Alguns dados da realidade}

Nos anos 80 , em virtude dos conflitos bélicos existentes na América Central, um grande número de centro-americanos teve que emigrar de seus países de origem para outros países vizinhos da região. Tais populações caracterizamse, principalmente, pelo fato de serem camponeses pobres, analfabetos em sua maioria, e por fugirem da repressão e da violência interna desencadeada em seus países.

Guatemala, El Salvador e Nicarágua foram os países que geraram a maior quantidade de refugiados, os quais tiveram que deixar seus países de origem. Existem tamberm os "desplazados" internos, pessoas que tiveram de deixar seu lugar de origem para deslocar-se até outras zonas consideradas mais seguras dentro de seus próprios países. Todo esse movimento migratório externo e interno fez com que em março de 1991 existisse um volume de 876:000 pessoas "desplazadas" internas e 1.255 .384 refugiados (Cf. CIREFCA) na América Central e México. Tenha-se em conta que Costa Rica, Belize e México não contam com "desplazados" internos; são por sua vez, países receptores de refugiados. Da cifra de refugiados anteriormente mencionada, $89 \%$ são indocumentados ou refugiados não reconhecidos, restando somente $11 \%$ de refugiados com status reconhecido. México possui 446.000 refugiados, dos quais so $10 \%$ recebem acompanhamento oficial. Em sua maioria são de origem guatemalteca, constatando-se também grande quantidade de salvadorenhos. Na América Central, Costa Rica é o país que conta com o maior número de refugiados, 290.767, dos quais apenas $14 \%$ têm status de refugiados, ou seja, $86 \%$ são indocumentados, sendo a grande maioria nicaragüense (Cf. Castro J. Pacheco G. Panorama del Fenomeno Centroamericano, CSUCA, 1991, mimeo).

Tendo em conta que estes são dados gerais e aproximados, na medida em que a população indocumentada não é facilmente quantificável, observamos que o fenômeno dos refugiados numa região relativamente pequena em população - aproximadamente 23 milhões de habitantes - é um problema de grandes proporções, o qual atinge mais de $9 \%$ da população total da América Central.

Independente disso, há o problema da extrema pobreza na regiâo, bem como os regimes neoliberais que governam atualmente, os quais, através de programas de "Ajuste Estrutural", e respondendo aos interesses do Fundo Monetário Internacional, fazem com que os pobres fiquem cada dia mais pobres e os ricos cada dia mais ricos.

Com isso, a situação real de extrema pobreza e de sofrimento dos refugiados na América Central não mudou. Aparentemente, os processos oficiais da democratização propiciaram um estado de paz para a região, mas persistem as causas que induzem as pessoas a refugiar-se ou a sair do país. Vemos então que o perfil do refugiado centro-americano corresponde em sua maioria a um perfil histórico de pobreza e de violação dos direitos humanos, com deslocamentos contínuos e repetidas fugas. Não podemos comparar esta grande quantidade de refugiados com os refugiados políticos, apesar de que na década de 80 , a partir de fora, se tenta ou se tentou dar-lhes esta conotação. Assim é o drama humano de milhares e milhares de pobres camponeses, indígenas e marginalizados que, não tendo a possibilidade de construir projetos de vida dignos em seu lugar de origem, têm em comum o sofrimento.

Na América Central dos anos 80 foram gerados milhares de refugiados e "desplazados", não mudando substancialmente o problema humano de salvadorenhos, guatemaltecos e nicaragüenses. O Alto Comissariado das Nações Unidas para os Refugiados está implementando neste momento os mais intensos programas de repatriação. Os que trabalhamos com fins humanitários, em meio aos refugiados e aos setores populares, estamos conscientes de que a melhor solução para um refugiado é a repatriação, porém o problema com o qual nos de- 
frontamos hoje é muito complexo: os refugiados estão deixando de ser considerados como tais, para passar a engrossar as grandes listas de indocumentados. As cifras que mencionamos nos parágrafos anteriores são muito claras. Pois bem, independentemente dos números, creio que o mais importante é o problema humano dos milhares e milhares de refugiados e "desplazados" na América Central. No âmbito da perda de identidade, encontramos gente com problemas de língua, como os miskitos e outros grupos étnicos guatemaltecos. Porém, o grande número de pessoas refugiadas e "desplazadas" não sofre severos problemas de aculturação, como poderia acontecer caso se transladassem para países do hemisfério norte.

\section{Uma experiência de trabalho}

No meu caso particular, faz nove anos que trabalho com uma equipe interdisciplinar atendendo refugiados na América Central. Consideramos a interdisciplinariedade de vital importância para esse trabalho. Não é possível isolar o problema das pessoas, grupos e comunidades inteiras que historicamente têm sido reprimidas e maltratadas por programas assistenciais considerados modelos. O problema do assistencialismo dos primeiros cinco anos de trabalho com os refugiados (1980-85) provocou danos profundos de dependência e processos regressivos em grande parte da população. Por um lado, tivemos experiências muito positivas, mas por outro, o fato de manipular indiscriminadamente doações dos programas das Nações Unidas (ACNUR) e de outros organismos internacionais desencadeou na década que estamos iniciando uma grande mudança Política por parte dos que decidem sobre os programas. Considerando que, humanamente falando, durante muitos anos as pessoas e respectivos programas foram tratados como prioritários, hoje, de acordo com estratégias das próprias Instituições Internacionais, tudo muda. Mudam as circunstâncias externas, e as mesmas pessoas, pobres e migrantes, deixam de ser chamadas de refugiados e passam a ser consideradas migrantes econômicos, e com isso são excluídas da prioridade de qualquer programa.

O trabalho com os refugiados centro-americanos, desde o início, foi centralizado nas zonas rurais, semelhantes a seus lugares de origem. Nos primeiros cinco anos lutamos contra as ajudas de emergência, considerando mais importante a dignidade do refugiado mediante seu trabalho. Trabalhamos especificamente na Costa Rica com refugiados salvadorenhos, nicara- güenses e guatemaltecos. Atuamos em coordenação com instituições e organismos de toda a América Central, especificamente com refugiados e "desplazados". O trabalho com refugiados, se podemos dizer assim, concentrou-se em grupos, comunidades rurais produtivas, grandemente voltadas a um projeto de vida para toda a América Central, sem excluir o trabalho que paralelamente se desenvolve de modo específico, no que se refere à saúde mental das pessoas afetadas pela violência organizada. Neste aspecto, consideramos que os modelos de abordagem em atenção aos refugiados centro-americanos no que se refere à saúde mental não podiam ser enfocados somente a partir de um ponto de vista clínico ou de denúncia contra os Direitos Humanos. A atenção ao refugiado é considerada a partir do ponto de vista integral e complexo em que a problemática psico-social é incorporada ao trabalho produtivo, educativo e jurídico, no âmbito da vida dessas pessoas. Levando-se em conta que o trauma provocado pela guerra na América Central é um trauma que abarca toda a vida das pessoas envolvidas, não podemos dar respostas focalizadas nem parciais, dada a complexidade do problema.

$\mathrm{O}$ trabalho em equipes interdisciplinares inclui profissionais de diferentes disciplinas, os quais, buscando dar uma dimensão integral à solução dos problemas, contribui cada qual com sua parte. Este modelo, que consideramos adequado, passa por uma constante revisão metodológica, onde os modelos abstratos e alheios a realidade são descartados.

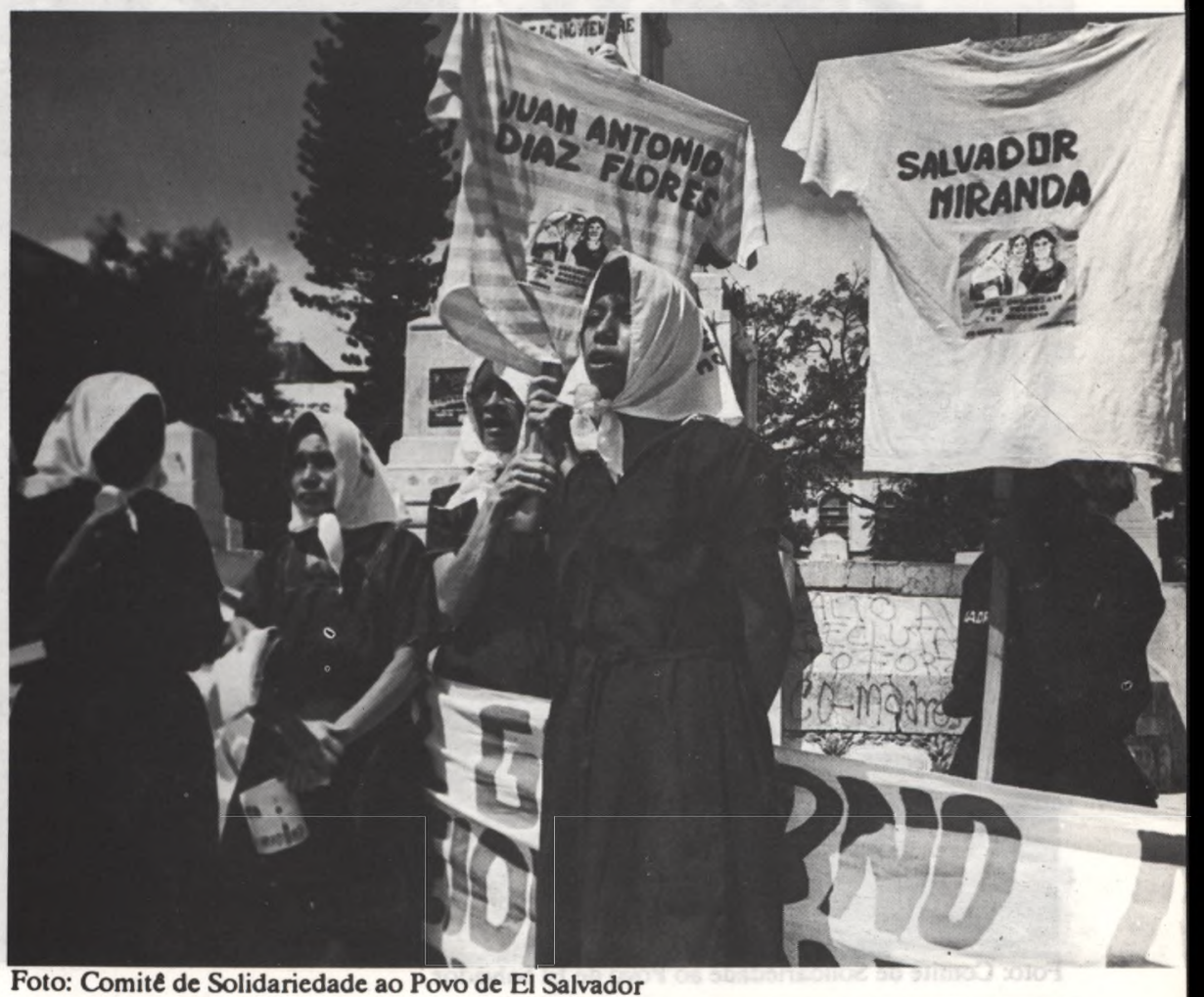




\section{Perspectivas e desafios}

A partir de um enfoque multidisciplinar, com uma metodologia integrada em seus aspectos psico-sociais e técnicos, temos como meta a reabilitação das vítimas da guerra através de sua incorporação ao trabalho, no sentido de conseguir uma verdadeira dignificação dos refugiados mediante o trabalho produtivo, bem como conseguir a auto-subsistência psico-social e económica. Nesse contexto é que se trabalha com os refugiados e os setores populares. Pois bem, o problema que enfrentamos na América Central com a abordagem de todas essas temáticas é complexo. Os próprios profissionais recém saí- dos das universidades muitas vezes encontram dificuldades para trabalhar em termos que possam romper com as estruturas academicistas de que provêm. É aqui onde o fator compromisso começa a jogar um papel relevante, em que o profissional deve libertar-se de estruturas tradicionais, que muitas vezes revelam sua insegurança em tratar de realidades tão complexas, as quais demandam uma sensibilidade e solidariedade específicas, dada a alta vulnerabilidade que apresenta a população.

O fenômeno dos refugiados na América Central, hoje, em abril de 1991, tem um perfil que tende a se configurar nos setores oficiais como o momento talvez mais difícil de enfrentar, uma vez que diminui fortemente a ajuda internacional. No entanto, embora o problema

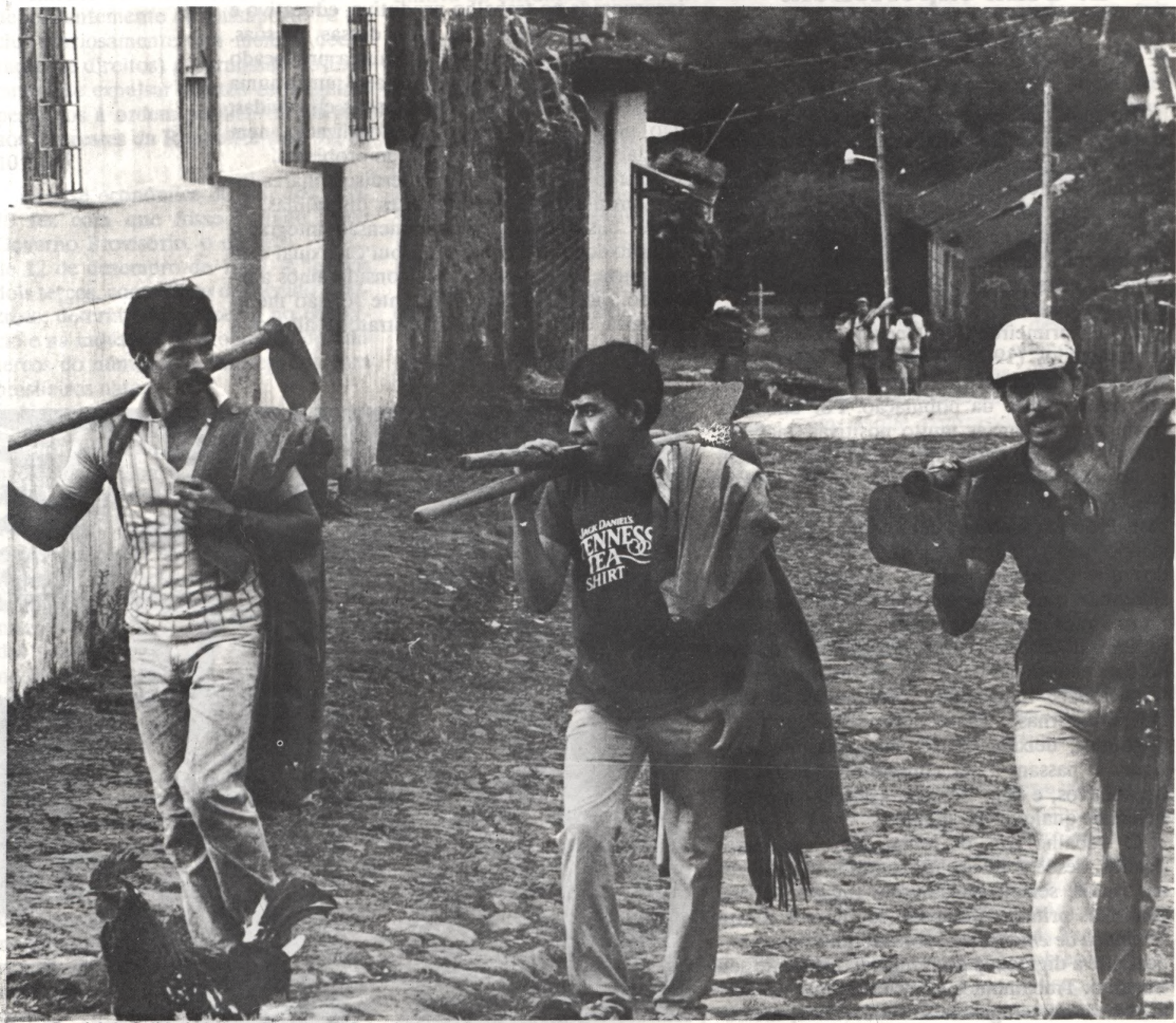

Foto: Comite de Solidariedade ao Povo de El Salvador 
bélico não esteja tão presente, salvo em El Salvador e na Guatemala com sériạs violações dos Direitos Humanos, a situação se mantém em muitos aspectos, mudando porém as políticas e o interesse pela ajuda a essas pessoas.

Esta é a situação em que nos encontramos atualmente, na América Central. As organizações não governamentais que trabalham com os refugiados, "desplazados ", "retornados" e indocumentados, associam-se em um grande esforço regional e nacional nos países centroamericanos, no sentido de buscar soluções dignas desde o ponto de vista do desenvolvimento integral; soluções a longo prazo, sem assistencialismos, conscientes de que a prioridade é a repatriação, entendida porém como retorno. Nesta perspectiva, coordenamos ações através das organizações não governamentais, partilhando pontos de vista interdisciplinares, onde o refugiado é sujeito ativo de suas próprias decisões.

Finalmente, consideramos de grande importância o fato de dar a conhecer o verdadeiro problema dos refugiados e "desplazados" na América Central. O problema da miséria, da violação dos Direitos Humanos, do sofrimento das pessoas que deixaram seus lugares de origem e se viram obrigadas a deslocar-se - tudo isso continua. As políticas neoliberais, as exigências do Fundo Monetário Internacional con- tinuam gerando pobreza e miséria. O problema migratório continua com suas duas variáveis principais: a extrema pobreza e o trauma da guerra. Essa é a nossa realidade, hoje, na América Central.

Talvez já não se lhes chame refugiados da guerra na América Central, mas a verdạde é que se continua a produzir os problemas que originaram essas migrações forçadas.

As soluções ao problema dos refugiados $\mathrm{e}$ "desplazados" na região não podem esperar. Devemos envidar todos os esforços conjuntos possíveis para solidarizar-nos com eles. Os milhares de refugiados, "desplazados" e indocumentados são pessoas que sofrem a perda constante de coisas preciosas a cada um, tais como: seu país, seus bens, seus costumes, sua linguagem, suas terras. As soluções, portanto, deverão respeitar continuamente sua cultura, sua religião, sua ıética , sua identidade.

(1) Este artigo foi traduzido do original espanhol por Sidney da Silva.

- Gabriela Rodríguez P. é Psicologa Social; coordenadora da Equipe Interdisciplinar que trabalha com os refugiados centro-americanos - El Productor - em São José da Costa Rica; membro da equipe centro-americana de Trabalho Psico-social e desde 1982 atua junto ds populações refugiadas e aos povos indigenas na América Central.

\section{EVENTO}

\section{SEMANA SOCIAL BRASILEIRA}

Data: 03 a 08 de novembro de 1991

Local: Instituto Israel Pinheiro Brasília/DF

Tema: Mundo do Trabalho - Desafios e Perspectivas no Brasil Hoje

Promoção: ĆNBB - Setor Pastoral Social

Participantes: Pessoas envolvidas com a questão do Mundo do Trabalho

Informaçôes: Fone - (061) 225.2955

CNBB - Setor Pastoral Social (vagas limitadas)

\section{LANÇAMENTO}

ESPINHOSO CAMINHO

PARA A LIBERDADE

Conflitos no Campo - 1990

CPT - Comissão Pastoral da Terra,

Ed. Loyola, 1991, 64 pp.

$A C P T$, mais uma vez, num trabalho minucioso, sério e comprometido, oferece ao público o relatório anual sobre os Conflitos no

Campo, desta vez referente ao ano de 1990.

Trata-se de uma fonte rica (e triste) de informaçöes acerca da realidade enfrentada pelos trabalhadores rurais e camponeses em geral do Brasil.

Esta publicação você não pode deixar de adquirir.

Maiores informaçōes: CPT - Caixa Postal: 749

CEP 74000 - Goiânia - GO - Fones: (062)

223.4039 / 224.4436 - Telex: (062) 2605-PTTC-BR 